\title{
The Scanning Electron Microscopy (SEM) And Energy Dispersive X-Ray Spectroscopy (EDS) For The Study Of The High Temperature Oxidation Mecanisms. The Microscopy In The Center of The 0thers Techniques (XPS, XRD, RAMAN and Glow Discharge...).
}

\author{
JM.Lameille $^{(1)}$, E. Buiret ${ }^{(1)}$, C. Berthier ${ }^{(2)}$ \\ (1) CEA, CE SACLAY, DCC/DPE, 91191 Gif sur Yvette Cedex FRANCE \\ (2) CEA, CE IDF/DPTA/SP2A/LEMI 91680 Bruyeres le Chatel
}

This paper is a part of a complete study on the influence of the minor elements (Al, Mn, Ti, Mo, Si, Nb, $\mathrm{Zr}, \mathrm{Y} . .$.$) on the high temperature oxidation mechanism of different alloys from stainless steels to nickel$ base alloys $[1,2,3$,$] .$

The purpose of it, is to show the interest of the scanning electron microscopy with $\mathrm{X}$ ray energy dispersive spectroscopy analysis (SEM-EDS) for the oxidation mechanism description and the others spectroscopies completes the understanding of the mechanism. .

The alloy used for this study is high temperature resistant alloy (ALFERON Y). The composition in wt $\%$ is: $\mathcal{F e} 6 a l ; \operatorname{Cr} 16 ; \mathcal{A l} 5 ; \mathcal{Y} 0.3 ; \mathcal{S}$ i $0.3 ; \mathcal{T} i \varangle 0.01 ; \mathcal{C} 0.03$, with a grain size of 50-100 $\mu \mathrm{m}$.

Sample coupons were cut from commercial alloy and mechanically polished, cleaned ultrasonically in ethanol and immediately dried. Heat treatments were performed in air at $1000^{\circ} \mathrm{C}$. After oxidation, the samples were examined by different surface-analytical spectroscopies including Scanning Electron Microscopy with $X$ ray Energy Dispersive Spectroscopy analysis (SEM-EDS), grazing X-ray Diffraction, RAMAN spectroscopy, $\mathrm{X}$ ray photoelectron spectroscopy and Glow Discharge Optical Spectroscopy.

Results :

1) The microscopy shows the diffusion of Aluminium and Titanium on the grain and the grain boundaries (fig 1). The oxide scale thickness increases with the heating time. The first table lists the results obtained on samples treated $5 \mathrm{mn}, 15 \mathrm{mn}, 1 \mathrm{~h}$ and $6 \mathrm{~h}$ at $1000^{\circ} \mathrm{C}$ and indicates that the scale is mainly constituted of aluminium oxide. After 6 Hours the $\mathrm{X}$ ray microanalysis shows the titanium in this scale. For the long time treatment the studies of the samples cross sections confirms this titanium oxide layer and the formation of a duplex structure with an external $\mathrm{TiO}_{2}$ scale and an inner $\mathrm{Al}_{2} \mathrm{O}_{3}$ scale (fig 2).

2) The XPS study completes those information by the underline of the titanium presence from $5 \mathrm{mn}$ of treatment. The figure number 3 presents the evolution of the chemical forms of the elements between the oxide scale surface to the alloy.

3) The Xray diffraction specifies the structures of the oxides, the titanium oxide is rutile and the aluminium oxide is corundum

4) The Raman spectroscopy presents the specific signals of rutile and alumina corundum, rutile only after 6 hours of treatment.

5) Glow discharge profiles confirms all the others information.

We know that it's necessary to have different information types about elementary compositions, chemical species and structural forms. The complementarity of the spectroscopies permits to describe the oxidation mechanism with the diffusion phenomena and shows the limitations of all the techniques. The difficulty is to take into account all the spatial resolutions and the limits of detection.

Ref:

1. JM. LAMEILLE et al ,Characterization of corrosion scales in FeNiCr alloys at high temperature by SEM and EDS. Micromat 96, Rio de janeiro 
2. F.DELAUNAY et al, Influence of the allowing additions on the high temperature oxidation of nickel base alloys, to be presented in EUROCORR'96 ( September 1996) Nice FRANCE

3. F.DELAUNAY Doctoral work : "Study of the minor elements influence on the oxidation mechanism of the nickel base alloys."

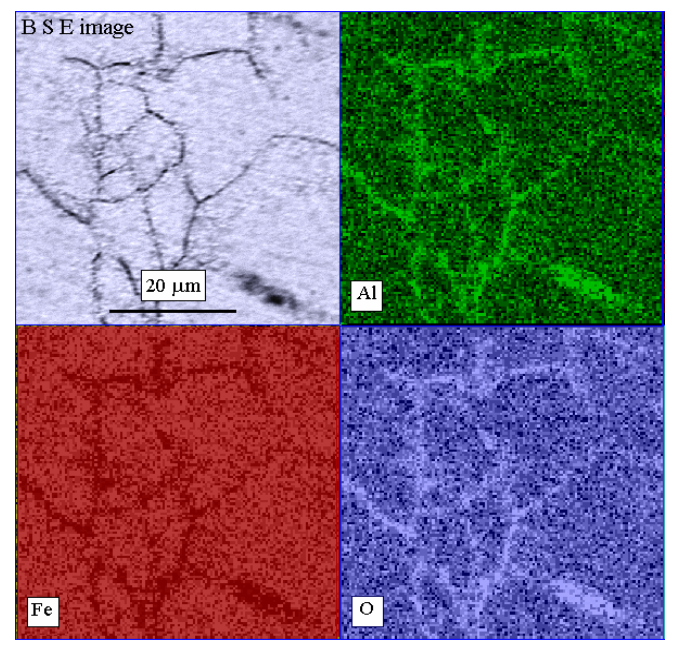

Fig 1: surface after $5 \mathrm{mn}$ at $1000^{\circ} \mathrm{C}$

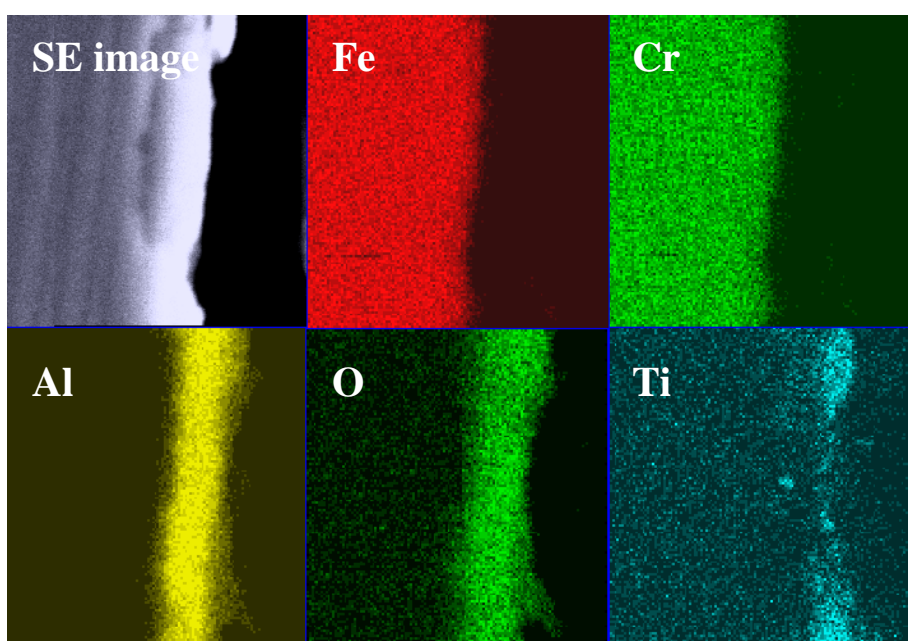

Fig 2: Oxides scale after 24 hours at $1000^{\circ} \mathrm{C}$

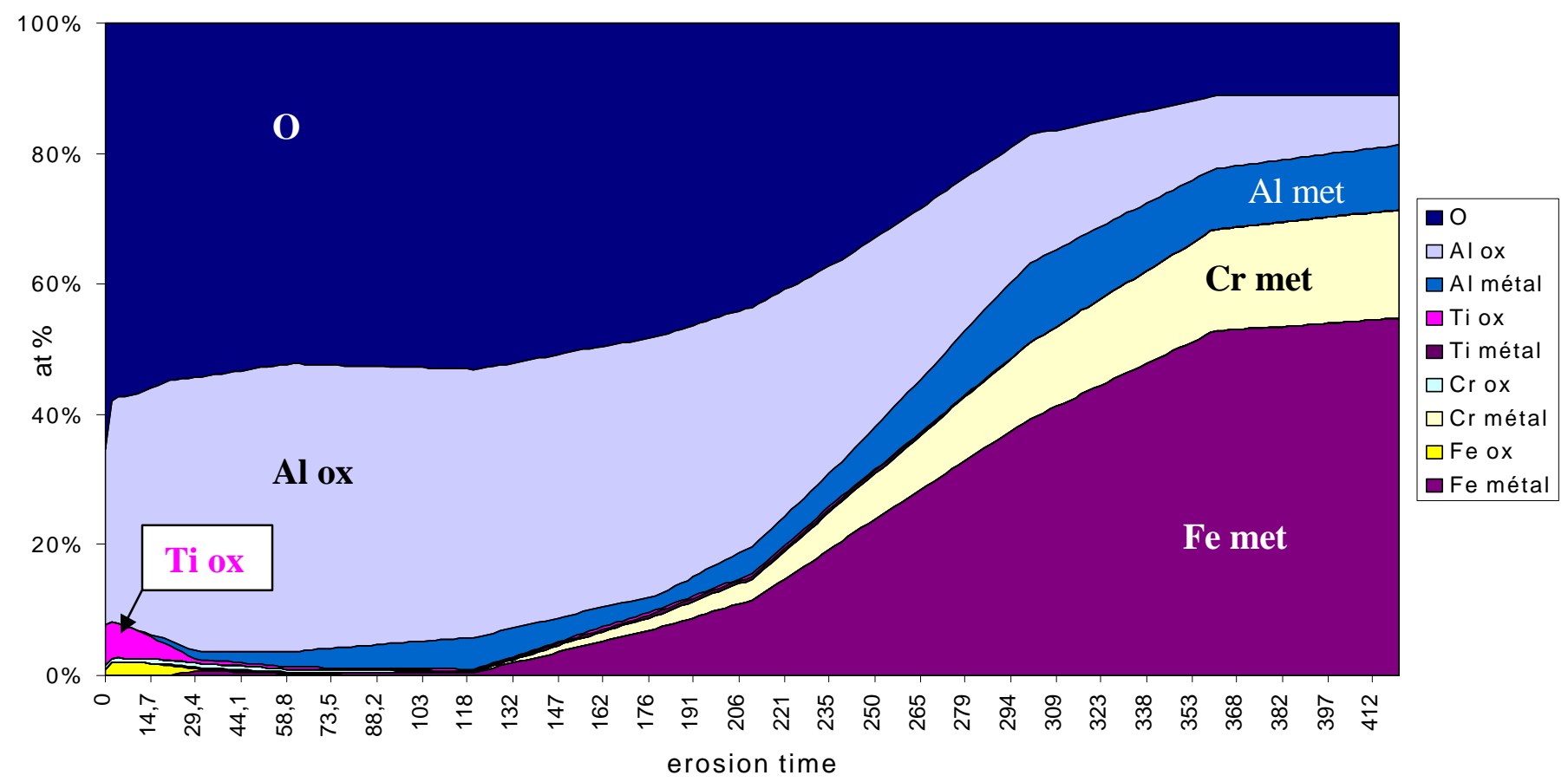

Fig 3: evolution of the elements species from the oxide scale surface to the alloy by electron spectroscopy XPS

\begin{tabular}{|l|c|c|c|c|}
\hline heating time & $5 \mathrm{mn}$ & $15 \mathrm{mn}$ & $1 \mathrm{~h}$ & $6 \mathrm{~h}$ \\
\hline$\% \mathrm{Al}$ in grains & $20 \%$ & $23 \%$ & $30 \%$ & $40 \%$ \\
\hline$\% \mathrm{Al}$ in grain boundaries & $25 \%$ & $30 \%$ & $40 \%$ & $50 \%$ \\
\hline
\end{tabular}

Table 1: evolution of the aluminium concentration at the surface, in the grains and in the grain boundaries (EDS results). 